\title{
First detection and characterization of Salmonella spp. in poultry and swine raised in backyard production systems in central Chile
}

\author{
R. ALEGRIA-MORAN ${ }^{1,2}$, D. RIVERA ${ }^{3}$, V. TOLEDO ${ }^{3}$, A. I. MORENO-SWITT ${ }^{3}$ \\ AND C. HAMILTON-WEST ${ }^{1 *}$ \\ ${ }^{1}$ Epidemiology Unit, Department of Preventive Veterinary Medicine, Faculty of Veterinary and Animal Sciences, \\ Universidad de Chile, Santiago, Chile \\ ${ }^{2}$ PhD Program in Agriculture, Forestry and Veterinary Science, Universidad de Chile, Santiago, Chile \\ ${ }^{3}$ Escuela de Medicina Veterinaria, Facultad de Ecología y Recursos Naturales, Universidad Andres Bello, \\ Santiago, Chile
}

Received 27 April 2017; Final revision 22 August 2017; Accepted 31 August 2017; first published online 20 September 2017

\section{SUMMARY}

Little is known about Salmonella serovars circulating in backyard poultry and swine populations worldwide. Backyard production systems (BPS) that raise swine and/or poultry are distributed across Chile, but are more heavily concentrated in central Chile, where industrialized systems are in close contact with BPS. This study aims to detect and identify circulating Salmonella serovars in poultry and swine raised in BPS. Bacteriological Salmonella isolation was carried out for 1744 samples collected from 329 BPS in central Chile. Faecal samples were taken from swine, poultry, geese, ducks, turkeys and peacocks, as well as environmental faecal samples. Confirmation of Salmonella spp. was performed using invA-polymerase chain reaction (PCR). Identification of serovars was carried out using a molecular serotyping approach, where serogroups were confirmed by a multiplex PCR of Salmonella serogroup genes for five Salmonella $\mathrm{O}$ antigens (i.e., D, B, C1, $\mathrm{C} 2-\mathrm{C} 3$, and E1), along with two PCR amplifications, followed by sequencing of $f l i C$ and $f j B$ genes. A total of 25 samples (1.4\% of total samples) from 15 BPS ( $4 \cdot 6 \%$ of total sampled BPS) were found positive for Salmonella. Positive samples were found in poultry (chickens and ducks), swine and environmental sources. Molecular prediction of serovars on Salmonella isolated showed $52.0 \%$ of $S$. Typhimurium, $16 \cdot 0 \%$ of $S$. Infantis, $16 \cdot 0 \% S$. Enteritidis, $8 \cdot 0 \% S$. Hadar, $4 \cdot 0 \% S$. Tennessee and $4.0 \% S$. Kentucky. Poor biosecurity measures were found on sampled BPS, where a high percentage of mixed confinement systems (72.8\%); and almost half of the sampled BPS with improper management of infected mortalities (e.g. selling the carcasses of infected animals for consumption). Number of birds other than chickens $(P=0 \cdot 014$; OR $=1 \cdot 04$; IC $(95 \%)=1 \cdot 01-1 \cdot 07)$, mixed productive objective $(P=0 \cdot 030$; OR $=5 \cdot 35$; IC $(95 \%)=1 \cdot 24-27 \cdot 59)$ and mixed animal replacement origin $(P=0017$; OR $=5 \cdot 19$; IC $(95 \%)=1 \cdot 35-20 \cdot 47)$ were detected as risk factors for BPS positivity to Salmonella spp. This is the first evidence of serovars of Salmonella spp. circulating in BPS from central Chile. Detected serovars have been linked to human and animal clinical outbreaks worldwide and in Chile, highlighting the importance of BPS on the control and dissemination of Salmonella serovars potentially hazardous to public health.

Key words: Backyard production systems, Salmonella spp., serotypification, surveillance, zoonotic agents.

\footnotetext{
* Author for correspondence: Dr C. Hamilton-West, Epidemiology Unit, Department of Preventive Veterinary Medicine, Faculty of Veterinary and Animal Sciences, Universidad de Chile, Santiago de, Chile. (Email: christopher.hamilton@veterinaria.uchile.cl)
} 


\section{INTRODUCTION}

The breeding of poultry and pigs in backyard production systems (BPS) represents a special concern in animal production due to its biosecurity and public health implications, especially in developing countries, due to its contribution to a household's livelihood [1]. This type of production is considered the most common form of animal production worldwide, where domestic poultry is the most commonly raised species; food products obtained from these BPS are usually consumed in homes, sold in informal local markets or exchanged as gifts [2].

In general, BPS are characterized by poor biosecurity measures and lower technological development, both in animal handling, and in the confined space used for animal production [3]. This leads to a high contact between humans and the species maintained in BPS, which are mainly birds (hens, chickens, ducks, geese, among others) and pigs [1]. BPS have the potential risk of entry of pathogens that can infect animal populations and be transmitted to humans. Usually, sick animals from BPS are sold, slaughtered and consumed, without considering the risk of zoonotic infection [4]. Additionally, these production systems are normally associated with low-income populations, where BPS is the primary source of income [5]. These communities may have limited transport and/or limited access to healthcare [6].

Salmonella spp. represent a diverse group of Gram negative Enterobacteria [7]. Currently, there are only two known species: Salmonella enterica and Salmonella bongori [8]. To date, up to six subspecies of Salmonella enterica and over 2600 different serovars have been identified. Importantly, certain isolates of important serovars, such as Typhimurium and Enteritidis, have shown demonstrated high virulence and resistance to multiple antibiotics [9, 10]. Factors such as wide distribution of Salmonella enterica in the environment, its prevalence in the global food chain production and pathogen virulence and adaptability; mean that Salmonella have had major economic impact on public health, estimated at $\$ 11.6$ billion [11]. Over the last decade, disease outbreaks have increased in Chile, and the rest of the world, [12, 13] along with increased detection of antibiotic-resistant serovars [10, 14, 15], highlighting the impact of Salmonella infections on global public health.

According to the last laboratory surveillance bulletin of Salmonella spp. (2017) from the Chilean Public Health Institute (ISP, by its Spanish acronym), a total of 11181 isolates of Salmonella spp. were confirmed from human clinical samples (e.g., stools) between the years 2012 and 2016, with an increase in the number of cases being reported during the hottest-season (November-March). These clinical isolates were mainly from patients in the Metropolitana and Valparaiso regions $(45.5 \%$ and $11.0 \%$, respectively). Annual incidence of Salmonella spp. in human clinical cases, ranged from $12 \cdot 0 \%$ to $17 \cdot 6 \%$ for this period. The main four serovars detected in human clinical cases were $S$. Enteritidis, $S$. Typhimurium, $S$. Typhi, and $S$. Paratyphi B $(60 \cdot 6 \%, 13 \cdot 7 \%, 1.9 \%$ and $1 \cdot 4 \%$, respectively) [16].

There is limited available information on the prevalence of Salmonella spp. in backyard chickens. Some studies have reported Salmonella presence ranging from $3.5 \%$ to $10 \cdot 4 \%$ of isolation rate at individual level and prevalence between $0.02 \%$ and $66.7 \%$ at a farm level $[3,17,18]$. The situation of Chilean BPS is similar to the rest of the world, with only local surveys being conducted. These surveys have identified Salmonella spp. in BPS located in the vicinity of national parks, where $1.3 \%$ of samples taken were positive for Salmonella spp. in BPS near 'Reserva Nacional El Yali' (Salas, R., unpublished observations); $4 \cdot 2 \%$ at the coast of Libertador General Bernardo O'Higgins region (Dépraz, S., unpublished observations) and $36.7 \%$ of samples at the valley of Libertador General Bernardo O'Higgins region (Gomez, E., unpublished observations). Positive samples were always found in fowls. The current study aimed to detect and characterize serovars of Salmonella spp. circulating in poultry and/or pigs raised in BPS in central Chile.

\section{MATERIALS AND METHODS}

\section{Study design and sample size}

The present study was carried out in three regions of central Chile: Valparaíso, Metropolitana de Santiago, and Libertador Bernardo O'Higgins (O'Higgins LBG) (Fig. 1). Commercial production of poultry and swine is heavily concentrated in this area. Similarly, this area has the most significant number of poultry and/or pigs bred in BPS in Chile [19]. Each study unit was defined as a BPS rearing poultry and/or pigs. Only BPS with up to 100 poultry and/or 50 pigs were included.

A proportional stratified random sampling approach was used, based on the 15 provinces included in the study area, using a random allocation of sampling points, as previously described [20]. Equation (1) was 

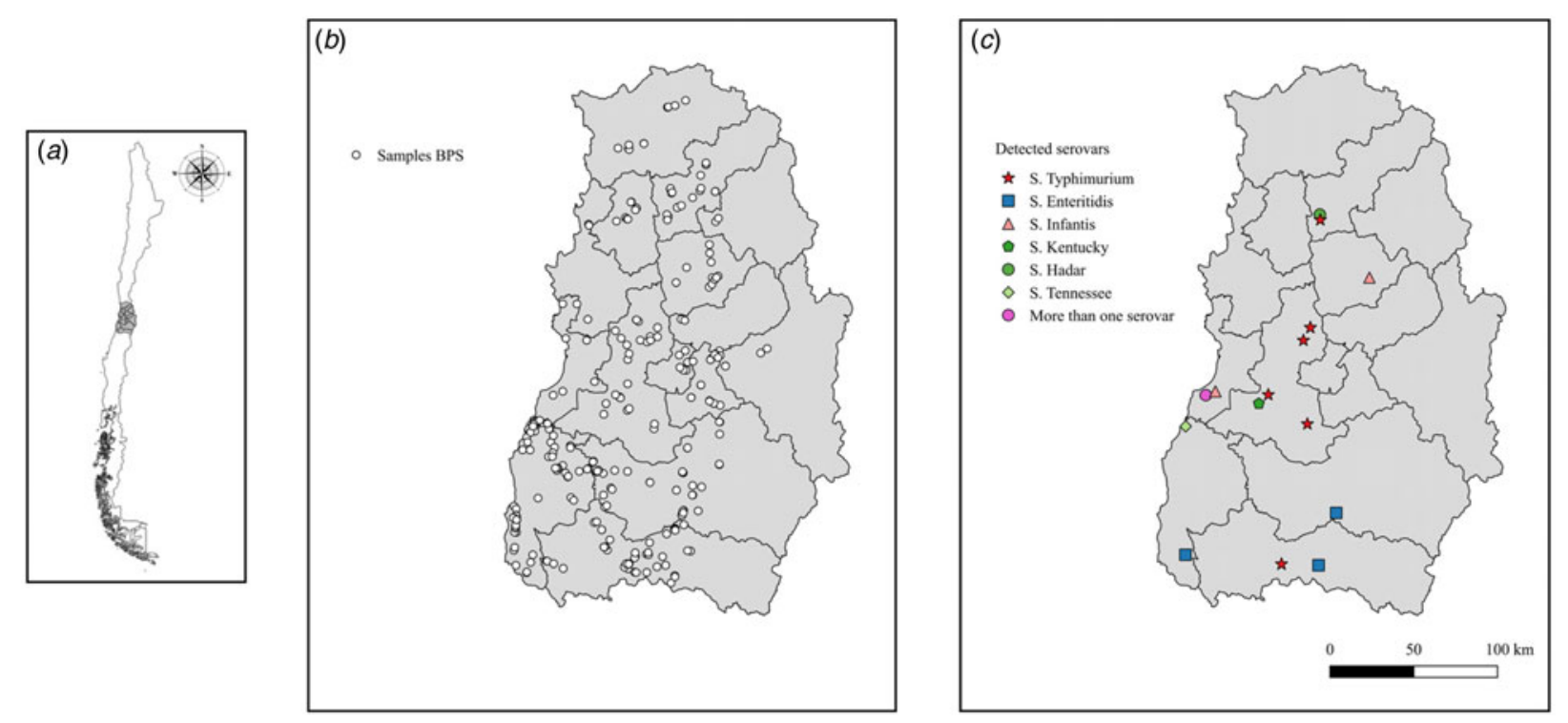

Fig. 1. Spatial distribution of Salmonella spp. identified at BPS level in central Chile. Location of study area in the context of Chile $(a)$. Location of sampled BPS in the study area (b). Results of identified serovars in study area $(c)$.

used adjusted by equation (2) to estimate the sample size [21]:

$n=Z_{\alpha}^{2} \mathrm{pq} / L^{2}$

where $n=$ sample size, $Z_{\alpha}=$ the value of $Z_{\alpha}$ required for confidence level $=1-\alpha$, where $\alpha$ corresponds to the level of confidence; $Z_{\alpha}$ is the percentile of a standard normal distribution $(1-\alpha / 2) ; p=$ the expected prevalence of the pathogen, $\mathrm{q}=(1-\mathrm{p})$ and $\mathrm{L}=$ the precision of the estimation, also known as 'allowable error' or 'margin of error'.

$n^{\prime}=1 /((1 / n)+(1 / N))$

where $n^{\prime}=$ the adjusted sample size, $n=$ the previous calculated sample size (eq. 1), $\mathrm{N}=$ the number of BPS in central Chile (population size). Assuming lack of knowledge about the prevalence of Salmonella spp. in BPS located in central Chile, sample size was calculated based on a prevalence of $50 \%$, ensuring maximum sample size possible when using an estimating a proportion approach [21], a confidence level of $95 \%$ and a precision of $5 \%$. Pigs reared on BPS were used for sample size calculation, assuming that they would also breed poultry, the number of BPS, by province, were obtained from the last available agricultural census from 2007 [19, 20]. A final sample size of 329 BPS was used (Table 1). For the intra-BPS sample size, we considered an approach for detecting Salmonella spp. using equation (3), which was not affected by population size [21]:

$n=\ln \alpha / \ln (1-p)$

where $n=$ sample size, $\alpha=$ type I error or $1-$ confidence level and $\mathrm{p}=$ the expected prevalence of the pathogen. Due to lack of information, a prevalence of $30 \%$ was assumed to identify at least one positive animal in each BPS in accordance with the last Chilean finding (Gomez, E., unpublished observations) and 95\% confidence level. A maximum intra-BPS sample size of nine birds and eight pigs was assumed to represent sanitary status of the sampled BPS. Nevertheless, a minimum of five samples were collected, and, in cases where there were less than five animals in the farm, all were sampled. Sampling included all poultry species and pigs present in the BPS.

A random process was performed to allocate BPS in the study area, once a BPS was located, to verify that poultry were kept and/or swine were produced, each BPS was invited to participate voluntarily in the study by signing an informed consent specifying the aim of the study, the responsible researcher and contact details (email and telephone number) in case of requiring further information of the project.

In the case of birds, cloacal samples were collected, using sterile swabs and then placed in Cary-Blair transport medium $\left(\right.$ Copan $^{\circledR}$, Italy). In the case of pigs, rectal samples were collected using sterile swabs and kept in Cary-Blair transport medium. Samples were labelled with the identification of the BPS and species. Where possible, environmental 
Table 1. Salmonella spp. isolation and PCR to invA gene confirmation results, sampled from backyard production systems in provinces of three regions in central Chile

\begin{tabular}{lllll}
\hline \hline & & \multicolumn{2}{c}{ BPS } & \\
\cline { 2 - 4 } & & Salmonella & PCR \\
Region & Province & $\begin{array}{l}\text { Sample } \\
\text { size }\end{array}$ & $\begin{array}{l}\text { isolation } \\
(\%)\end{array}$ & $0(0 \cdot 0)$ \\
\hline Valparaíso & Petorca & 15 & $2(13 \cdot 3)$ & $0(0 \cdot 0)$ \\
& Valparaiso & 5 & $1(20 \cdot 0)$ & $0(0 \cdot 0)$ \\
& Quillota & 9 & $2(22 \cdot 2)$ & $2(10 \cdot 0)$ \\
& San Felipe & 20 & $2(10 \cdot 0)$ & $0(0 \cdot 0)$ \\
& Los Andes & 2 & $0(0 \cdot 0)$ & $2(20 \cdot 0)$ \\
Metropolitana & San Antonio & 10 & $2(20 \cdot 0)$ & $1(9 \cdot 7)$ \\
& Melipilla & 30 & $5(16 \cdot 7)$ & $0(0 \cdot 0)$ \\
& Chacabuco & 11 & $1(9 \cdot 1)$ & $0(0 \cdot 0)$ \\
& Santiago & 9 & $1(11 \cdot 1)$ & $0(0 \cdot 0)$ \\
& Cordillera & 4 & $1(25 \cdot 0)$ & $0(0 \cdot 0)$ \\
LGB O'Higgins & Talagante & 5 & $0(0 \cdot 0)$ & $2(2 \cdot 2)$ \\
& Maipo & 13 & $0(0 \cdot 0)$ & $1(2 \cdot 1)$ \\
& Cardenal Caro & 90 & $8(8 \cdot 9)$ & $2(3 \cdot 4)$ \\
Total & Cachapoal & 47 & $5(10 \cdot 6)$ & $15(4 \cdot 6)$ \\
\hline \hline
\end{tabular}

samples were also collected from fresh faeces from feeders, nesting material, floors of the poultry or pig pens, using sterile swabs with Cary-Blair transport medium. These samples were labelled with the identification of the BPS plus a code to identify that samples were collected from the environment. All samples were transported and stored at $4{ }^{\circ} \mathrm{C}$ until processed. Samples were collected during the period from July 2013 to April 2015 and each BPS was sampled once.

\section{Salmonella isolation}

Samples were processed at the Centralized Veterinary Research Laboratory (Universidad de Chile), within 5 days of collection. The method of bacterial culture was performed in three stages [22]; (i) Selective pre-enrichment: faecal content of the swab was inoculated with $5 \mathrm{ml}$ of Phosphate Peptone Water Broth (APT, Difco ${ }^{\circledR}$ ) supplemented with $20 \mathrm{mg} / \mathrm{ml}$ novobiocin $\left(\right.$ Sigma $\left.{ }^{\circledR}\right)$ [23] and mixture was incubated at $37^{\circ} \mathrm{C}$ for 18 to $24 \mathrm{~h}$; (ii) Enrichment: $200 \mu \mathrm{l}$ of the pre-enrichment suspensions were inoculated into three equidistant drops on Modified Semi-solid Rappaport Vassiliadis (MSRV, Oxoid ${ }^{\circledR}$ ) supplemented with $20 \mathrm{mg} / \mathrm{ml}$ novobiocin $\left(\right.$ Sigma $\left.^{\circledR}\right)$, and then incubated at $42{ }^{\circ} \mathrm{C}$ for $24-48 \mathrm{~h}$, to detect motile Salmonella serovars [24]. Samples displaying a halo of growth white/gray, opaque or diffuse around the inoculation site, with well-defined edges, were considered suspicious and moved to the third culture phase; and (iii) Selective isolation: samples compatible with growth and/or diffusion were sub-cultured by exhaustion on Xylose Lysine Deoxychocolate (XLD, Difco ${ }^{\circledR}$ ) agar and incubated at $37^{\circ} \mathrm{C}$ for $24 \mathrm{~h}$. Samples with development of red colonies with black centre or translucent colonies were suspected to be Salmonella spp.

\section{Confirmation and identification of Salmonella serovars}

Confirmation was made by polymerase chain reaction (PCR). Amplification was performed using primers for detection of $284 \mathrm{bp}$ amplicon of invA gene. A positive control ( $S$. enterica, donated by the Infectious Diseases Laboratory, FAVET-Universidad de Chile) and a negative control (no addition of DNA) were also included. The detailed conditions of PCR are described by Malorny, Hoorfar [25].

Samples confirmed as positives with PCR were serotyped using a molecular serotyping approach at Universidad Andrés Bello (UNAB), as previously described [26]. Briefly, Salmonella DNA was extracted following the protocol of QIAamp DNA mini kit (Qiagen, Valencia, CA, USA). DNA concentrations and quality were quantified using 260/280 ratios 
using a Synergy 2 Multi-Mode Reader (Biotek, Vermont, USA). PCR was performed using two separated PCRs for amplification of $\mathrm{AlC}$ (encodes $\mathrm{H} 1$ antigen) and $f j B$ (encodes $\mathrm{H} 2$ antigen) genes using previously published primers and PCR conditions $[26,27]$. PCR products were purified and both strands were sequenced at Macrogen, Inc (Seoul, Korea). Raw sequences were manually edited to build a consensus. The BLAST algorithm was used to identify the best matched sequence at NCBI nucleotide database. Serovar was confirmed by a multiplex PCR detection of the Salmonella serogroup genes for five Salmonella $\mathrm{O}$ antigens: D, B, C1, C2-C3, E1 [26].

\section{Data analysis}

A survey was conducted on each BPS by a semistructured interview with BPS owners, where data was collected in relation to infrastructure, biosecurity and trade elements. Salmonella spp. prevalence at individual and BPS level were then estimated. Descriptive statistics analysis was conducted in relation to infrastructure, biosecurity and trade practice with the aim of describe BPS activities. BPSs were then classified as positive (at least one PCR positive sample to Salmonella spp.) or negative. Given the nature of the collected information (BPS positive or negative to Salmonella spp., binary or dichotomous response) a logistic regression model analysis was performed, where $\mathrm{Y}$ (response) can have only two values, 0 or $1(\mathrm{Y}=0$ or $\mathrm{Y}=1)$, representing the absence $(0)$ or presence (1) of the studied agent [21]. The aim of the regression analysis is to identify potential risk factors for BPS positivity to Salmonella spp. A univariate analysis was performed for the selection of the variables to be included in the final model. Variables with a $P$-value $\leqslant 0 \cdot 25$ were selected to the multivariable logistic regression model, where the outcome variable was the presence/absence of Salmonella spp. in the BPS. The model with the lowest log Likelihood Ratio Test (LRT) was selected as the final model [28], using a stepwise backward elimination procedure removing those variables whose regression coefficients were not significant $(P>0 \cdot 05)$. Non-significant variables, which produced a change of $\geqslant 20 \%$ in the regression coefficients of the significant variables when removed, were retained in the model to adjust for confounding factors [21]. Goodness-of-fit was assessed using the Hosmer and Lemeshow Test [29].

\section{Ethics statement}

All sampling activities, informed consent and survey protocols were approved by the ethics and biosecurity committee of Faculty of Veterinary Science (FAVET), University of Chile, and all field activities were performed by trained veterinarians or veterinary students.

\section{RESULTS}

Salmonella spp. detection and characterization at BPS level

A total number of 1744 samples were collected from 329 BPS, consisting of 95 environmental samples $(5 \cdot 4 \%), 81$ swine samples $(4 \cdot 6 \%), 1461$ poultry samples $(83.9 \%), 10$ goose samples $(0.6 \%), 63$ duck samples $(3 \cdot 6 \%), 33$ turkey samples $(1 \cdot 8 \%)$ and 1 peacock sample $(0 \cdot 1 \%)$. In the bacteriological culture, a total of 47 samples $(2 \cdot 7 \%$ of the total) were considered to be Salmonella spp. colonies, corresponding to 33 (10.0\%) positive BPSs (Table 1). Conventional PCR to detect invA gen, confirmed 25 samples as Salmonella spp. positive $(48.9 \%$ from the suspected samples, $1 \cdot 4 \%$ of the total analysed samples), where these samples were collected from 15 BPS (4.6\% from total sampled BPS). A total of $72.0 \%$ of the positive samples were collected from chickens, with positive samples being collected also from ducks $(12 \cdot 0 \%)$, pigs $(8.0 \%)$, and in samples obtained from the environment in which the animals were kept $(8 \cdot 0 \%)$. Positive samples were also found in the Provinces of San Antonio (20.0\%), Melipilla (16.7\%), San Felipe (10.0\%), Chacabuco $(9 \cdot 1 \%)$, Colchagua $(3 \cdot 4 \%)$, Cachapoal $(2 \cdot 1 \%)$ and Cardenal Caro $(2 \cdot 2 \%)$. At a regional level, Metropolitana de Santiago had higher prevalence $(8 \cdot 3 \%)$ followed by Valparaiso region $(6 \cdot 6 \%)$ and finally O'Higgins LBG region $(2 \cdot 6 \%)$. Interestingly, positive samples from San Felipe and Colchagua provinces were found for both multiple species (poultry, swine and ducks) and environmental samples. Molecular prediction of serovars on Salmonella isolated showed $52.0 \%$ of Salmonella Typhimurium, $16.0 \%$ of Salmonella Infantis, $16 \cdot 0 \%$ Salmonella Enteritidis, 8.0\% Salmonella Hadar, 4.0\% Salmonella Tenessee and $4.0 \%$ Salmonella Kentucky (Table 2) (Fig. 1).

\section{Differences in biosecurity across BPS}

A total of 329 BPS were identified in the study area. The total number of animals in these farms was 13513 
chickens; 1005 ducks; 506 turkeys; 419 geese and 376 pigs. In terms of the BPS main productive objective, most of them declared an objective different to agricultural activities (52.6\%) (e.g. mechanical workshop, security post, hostel), followed by livestock breeding $(23.6 \%)$ (e.g. organic meat production, free range egg production, sale or lease of animals for reproduction), mixed objective (16.3\%) (e.g. BPSs that declared to function as hostel and sells animals and animal products) and agriculture $(7 \cdot 9 \%)$ (e.g. crops).

In terms of the consumption of animals or animal products originated in the BPS, only 27 BPS $(8 \cdot 2 \%)$ declared not consuming eggs produced by their hens. Of those BPS that declared to consume eggs, presented a monthly average consumption of $49 \cdot 1$ eggs. All BPS declared to eat chicken reared on site, declaring a monthly average of chicken consumption of almost three birds $(2 \cdot 7$ birds $)$. No records were detected regarding pig meat consumption, because it is mainly used for sale, trade for other products, or as gifts for family holidays or traditional celebrations.

In terms of biosecurity practices, $85.4 \%$ of the BPS owners did not perform any disinfection (e.g. handwashing) prior to contact with animals; while only $29.5 \%$ of the BPS owners did not perform any disinfection after animal contact. A total of $72.8 \%$ of the BPS owners ran a mixed confinement system, i.e., free ranging during the day and confined during night, $15 \cdot 8 \%$ were free-range systems and $11 \cdot 4 \%$ were permanent confinement systems (e.g. stabling animals). Furthermore, $62.9 \%$ reported no contact between their animals and neighbours' animals. Only $29 \cdot 6 \%$ of BPS owners declared to have functional fences (confirmed with visual inspection of the BPS), and $70.4 \%$ had no fencing on the BPS. In relation to Veterinary assistance on the BPS, only $19 \cdot 3 \%$ reported any sort of assistance, private Vets or government agency Vets. When asked on how mortalities were handled, $46.7 \%$ reported inadequate disposal of dead animals, where deceased animals were sold or eaten, disposed in the household garbage, dumped in the nearest watercourse, fed to dogs or cats, or left on site (where decease animals remained untouched). $53.3 \%$ reported to apply proper actions, like burning or burying the deceased animals.

Variables related to biosecurity were incorporated to the multivariable logistic analysis. Final model with the lowest LRT included four of these factors $(P<0.05)$, Number of birds other than chickens, BPS productive objective, Animal replacement and Presence of Functional fences. Increasing the number of birds other than chickens had a significantly higher risk of becoming positive to Salmonella spp. [odds ratio (OR) $1 \cdot 04,95 \%$ CI 1.01-1·07], BPSs with a productive objective with mixed activities (agricultural and other non-agricultural) had a significantly higher risk (OR $5 \cdot 35,95 \%$ CI 1.24-27.59) compared with those with agricultural productive objective, BPSs using a mixed origin for animal replacement had a significantly higher risk (OR 5.19, 95\% CI 1.35-20.47) compared with those using own animal replacement (Table 3). The model presented a good fit to the data evidenced by the Hosmer-Lemeshow test $(P=0 \cdot 16)$.

\section{DISCUSSION}

Salmonella spp. is a well-known circulating pathogen in the poultry and swine industries in Latin America and beyond [30]; however, there are gaps in knowledge regarding its presence in human and animal cases of salmonellosis in Latin America. In addition, salmonellosis is extremely underreported, as clinical signs are self-limited in humans and normally not formally diagnosed, and may be absent in animals. This knowledge gap about Salmonella spp. becomes more clear and relevant at the BPS level where limited or no information is available about the circulation of this pathogen and other pathogens which have an impact on public health [4]. This is the first study that identified the presence of Salmonella serovars in BPS from central Chile.

The characteristics of BPS in terms of infrastructure and biosecurity measures allow ideal conditions for spread of pathogens like Salmonella spp. The prolonged and direct contact within different species maintained on each BPS and with the neighbour BPS, allows transmission of different serovars, and increases the chance of human infection, considering that these particular populations normally are associated with low-income population and with geographical and logistic restrictions to health care access $[5,31]$. This is strongly related to poor biosecurity measures present on BPS, for example, the mixed confinement allows the spread of the pathogen to susceptible animals [4]. The absence of functional fences and contact with wild animals and animals of neighbours increases the risk of transmission in a BPS [32]. Evidence has shown similarities between Salmonella Typhimurium multi-locus variable number tandem repeat analysis (MLVA) (isolated from foxes and wild birds) with MLVA types (isolated from chickens) and human food borne cases in 
Table 2. Predicted serovars and serogroup determination by multiplex $P C R$, and $\mathrm{H} 1$ and $\mathrm{H} 2$ antigen presence of positive samples from backyard production systems in provinces of three regions from central Chile

\begin{tabular}{|c|c|c|c|c|}
\hline Sample ID & Serogroup & $\mathrm{H} 1$ & $\mathrm{H} 2$ & Predicted serovars \\
\hline $\mathrm{CACH} 032-3$ & $\mathrm{D}$ & + & - & $S$. Enteritidis \\
\hline CACH032-4 & $\mathrm{D}$ & + & - & $S$. Enteritidis \\
\hline CC045-swine & & + & - & S. Tennessee \\
\hline CC089-2 & $\mathrm{D}$ & + & - & S. Enteritidis \\
\hline CHA004-3 & $\mathrm{C} 1$ & + & + & $S$. Infantis \\
\hline CHA004-4 & $\mathrm{C} 1$ & + & + & $S$. Infantis \\
\hline COL001-5 & $\mathrm{D}$ & + & - & S. Enteritidis \\
\hline COL033-env & $\mathrm{B}$ & + & + & S. Typhimurium \\
\hline COL033-duck_3 & $\mathrm{B}$ & + & + & S. Typhimurium \\
\hline ME006-4 & $\mathrm{B}$ & + & - & $S$. Typhimurium \\
\hline ME010-3 & $\mathrm{B}$ & + & - & S. Typhimurium \\
\hline ME014-3 & $\mathrm{B}$ & + & + & S. Kentucky \\
\hline ME015-2 & $\mathrm{B}$ & + & - & $S$. Typhimurium \\
\hline ME018-5 & & + & + & $S$. Typhimurium \\
\hline SF017-5 & $\mathrm{C} 2-\mathrm{C} 3$ & + & - & S. Hadar \\
\hline SF017-env & $\mathrm{C} 2-\mathrm{C} 3$ & + & + & S. Hadar \\
\hline SF020-1 & $\mathrm{B}$ & + & + & S. Typhimurium \\
\hline SF020-2 & $\mathrm{B}$ & + & + & S. Typhimurium \\
\hline SF020-3 & $\mathrm{D}$ & + & - & S. Typhimurium \\
\hline SF020-duck & $\mathrm{D}$ & + & - & $S$. Typhimurium \\
\hline SF020-duck_2 & $\mathrm{B}$ & + & + & $S$. Typhimurium \\
\hline SF020-swine & $\mathrm{B}$ & + & - & S. Typhimurium \\
\hline SA007-2 & $\mathrm{B}$ & + & + & S. Typhimurium \\
\hline SA007-3 & $\mathrm{C} 2-\mathrm{C} 3$ & + & + & $S$. Infantis \\
\hline SA008-2 & $\mathrm{C} 2-\mathrm{C} 3$ & + & + & $S$. Infantis \\
\hline
\end{tabular}

Australia [33]. As BPS are not usually assisted by veterinarians, they do not have adequate or control strategies should a sanitary event occur [4]. Similarly, in relation to handling of mortalities within the BPS, almost half of the surveyed BPS declared improper handling of dead animals, potentially affecting their own BPS or neighbours'. Evidence to suggest this was found with detection of Salmonella spp. in watercourses, which is linked to human cases of salmonellosis [15]. Space sharing with other species of domestic birds (e.g. turkey, goose, ducks, etc.) increase the risk of Salmonella spp. positivity, probably due to the close contact of these animals in BPSs, allowing these species to act as maintainer of pathogens at the potential infection of new susceptible animals $[18,34]$.

Gaps in knowledge can be identified in terms of Salmonella spp. status of BPS worldwide, where small-scale surveys show positive samples were found in backyard poultry or swine samples of $1.2 \%$ of the total sample on BPS from 'Reserva Nacional El Yali' (Salas, R., unpublished observations) and 4.2\% Libertador General Bernardo O'Higgins region (Dépraz, S., unpublished observations). Similar results have been described in poultry backyard production in Paraguay, where $3.5 \%$ of positivity was observed at district level [17]. Manning, Gole [3], detected a 13.3\% positivity to Salmonella spp. in chickens at BPS level in South Australia, reporting Salmonella Agona, Salmonella subsp 2 ser 21:z10:z6 (Wandsbek) and Salmonella Bovismorbificans. Jafari, Ghorbanpour [35], reported a $5 \cdot 8 \%$ of positivity from pooled samples from 35 BPS from Iran, 15\% of positivity in birds keep under BPS from the West Bengal region, India [36], suggesting similar positivity levels to Salmonella spp. on BPS at a province, regional or national level. Differences could be attributed to different dominant serovars in each country, the infection incidence on BPS and the sampling times and strategies. This small variation could be also attributable to differences in the health status of the backyard chickens in each country and the biosecurity measures and practices of each BPS [3].

Only two samples from pigs were positive for Salmonella serovars. This can be partially explained by the low sensitivity detection of faecal sampling, indicating that relative sensitivity will increase if the amount of faecal content increased [37], the occurrence of intermittent shedding of the agent following the exposure [38]; and the presence of Salmonella spp. epidemics without clinical manifestation [39]. This is important considering the nature of our study, which consists of cross-sectional sampling. Multiple repeated samples should be taken to reduce the effect of intermittent shedding [33]. However, the lifespan of animals in a BPS is very quick, considering that these animals are used as gift to family and friends, used as protein source and for trade for other products or animals.

The microbiological culture method used in this study is considered the 'gold standard' for Salmonella spp. detection [40] and PCR for invA gen detection have been reported to have a $98 \%$ of analytical accuracy [25]. The typing method used in this study has an accuracy of $85.7 \%$ for less common Salmonella serovars and $91 \cdot 3 \%$ for most common Salmonella serovars compared with the conventional methods [26]. The analytical tools used in this study are sensitive and specific enough to detect Salmonella spp. and to predict serovars from the sampled matrices. These results could be affected by the intermittent shedding 
Table 3. Results of the multivariable model for Salmonella spp. positivity at BPS level

\begin{tabular}{|c|c|c|c|c|c|c|c|}
\hline Variable & Classification & $\beta$ & S.E. $\beta$ & OR & Lower CI & Upper CI & $P$-value \\
\hline Intercept & & $-3 \cdot 310$ & $0 \cdot 775$ & 0.037 & $0 \cdot 008$ & $0 \cdot 167$ & $0 \cdot 000$ \\
\hline Number of birds other than chickens & & $0 \cdot 037$ & $0 \cdot 015$ & $1 \cdot 038$ & $1 \cdot 008$ & $1 \cdot 069$ & $0 \cdot 014$ \\
\hline \multirow{3}{*}{ BPS productive objective } & Agricultural & & & & & & \\
\hline & Mixed & 1.676 & $0 \cdot 773$ & $5 \cdot 345$ & $1 \cdot 240$ & $27 \cdot 591$ & 0.030 \\
\hline & Other & $0 \cdot 207$ & 0.776 & $1 \cdot 230$ & $0 \cdot 268$ & $5 \cdot 632$ & 0.790 \\
\hline \multirow[t]{3}{*}{ Animal replacement } & Own & & & & & & \\
\hline & Others & $-0 \cdot 940$ & $1 \cdot 109$ & $0 \cdot 391$ & $0 \cdot 044$ & $3 \cdot 432$ & $0 \cdot 397$ \\
\hline & Mixed & $1 \cdot 646$ & $0 \cdot 688$ & $5 \cdot 188$ & $1 \cdot 347$ & $20 \cdot 468$ & $0 \cdot 017$ \\
\hline \multirow[t]{2}{*}{ Functional fences } & No & & & & & & \\
\hline & Yes & $-1 \cdot 261$ & $0 \cdot 812$ & $0 \cdot 283$ & 0.058 & $1 \cdot 392$ & $0 \cdot 120$ \\
\hline
\end{tabular}

described for the species involved in this study [31, 35], underestimating the prevalence. As the aim of this study was to detect and describe BPS circulating Salmonella serovars, the impact of this is not significant, but could lead to missing some circulating serovars. Estimation of prevalence could be improved by the use of PCR and microbiological culture to gain more information about Salmonella spp. present in the population and to determine all potential serovars [41, 42]. Is important to acknowledge that not all the PCR positive samples were confirmed by the traditional Salmonella isolation as this technique requires viability of the agent, where PCR will only detect DNA presence [40, 43].

This study found that $S$. Typhimurium was present in over $50 \%$ of positive samples. $S$. Typhimurium is a motile, highly invasive serovar, which has adapted to survive outside of a host, and is one of the most common pathogens in human foodborne infections worldwide [44]. It is associated with poultry products, considering that laying hens are the most important reservoir [45], but is also linked to swine production and carcass contamination [46]. In Chile, $S$. Typhimurium was identified as the second most important serovar isolated from human clinical cases, between the year 2012 and 2016, with the $13.7 \%$ of the total isolated for the period [16].

The second most common serovar detected in this study was $S$. Infantis, also zoonotic [47], being detected not only in human gastrointestinal contents, but also in spleen, liver and lymphoid tissues, resulting in an infection behaviour similar to pigs and chickens, with temporal shedding of the agent, making detection more difficult [48]. This serovar has been linked historically to human outbreaks in the USA, related to live poultry from mail-order hatcheries [49]. Almost 220 cases affecting 39 states in the USA were related to contact with live poultry at BPS were detected in 2016 [50].

The third most common serovar identified in this study was $S$. Enteritidis, a zoonotic, highly invasive serovar, which is mainly associated with commercial layer flocks and causes egg-related food-borne illnesses in humans worldwide, particularly in the USA [51]. $S$. Enteritidis has also been isolated from free-range chickens in China [52], backyard poultry in the USA [53] and from feral pigeons in Brussels [54], constituting a significant reservoir for salmonellosis in urban and rural Environment. These three serovars have been isolated from Chilean watercourse from Metropolitana region, and have been linked to human outbreak-associated clinical isolates, mainly detected from rural areas. This indicates that animal husbandry and particularly BPS might contribute to the dissemination and distribution of this pathogen [15], and has been identified as the most historically important serovars, causing over the $60 \%$ of the human clinical cases of foodborne-illnesses in Chile [16]. Less common serovars, $S$. Hadar, $S$. Tenessee and $S$. Kentucky, are similar to the major serovars and have been linked to animals or animal products and associated with human clinical outbreaks [55-57]. Backyard raised animals may play an important role in the distribution and dissemination of Salmonella spp., considering the shedding of the pathogen to the environment, animal movement, poor biosecurity measures, and the mixing of animals of different species, ages and origins in production systems, disseminating the agent to new susceptible populations [58, 59]. Most BPS included in the study are in close proximity to free range or intensive commercial poultry and swine farms, with implications for horizontal transmission of Salmonella spp. and risk of human outbreaks. 


\section{CONCLUSIONS}

This is the first evidence of serovars of Salmonella spp. circulating at a regional and province level in BPS from central Chile. The three most important serovars detected on BPS were $S$. Typhimurium, $S$. Infantis and $S$. Enteritidis. All detected serovars have been linked to human and animal clinical outbreaks worldwide, indicating the importance of BPS in public health, due to close contact between holders and their animals.

Surveillance activities must be increased to identify if Salmonella serovars circulating in BPS are related to wild birds, poultry and swine commercial production systems, and human Salmonella serovars isolated during outbreaks. Furthermore, adequate pathogen control strategies must be adopted in BPS (such as improvements in biosecurity) to reduce risk of infection high-risk areas for Salmonella spp. infection.

\section{ACKNOWLEDGEMENTS}

This project was partially funded by FONDECYT 11121389 to CHW, FONDECYT 11140108 to AIMW and CONICYT 21130159 to RA-M. The authors acknowledge all in Epi-FAVET for their support on the field activities, Dr Patricio Retamal for training in laboratory activities, and $\mathrm{Dr}$ Matias Rojas for field and laboratory activities support. The authors acknowledge Dr Graham Lough for the English language, writing assistance and proof reading the article.

\section{DECLARATION OF INTEREST}

None.

\section{REFERENCES}

1. Conan A, et al. Biosecurity measures for backyard poultry in developing countries: a systematic review. BMC Veterinary Research 2012; 8: 240. doi: 10.1186/ 1746-6148-8-240.

2. FAO. Biosecurity for highly pathogenic avian influenza. Rome, Italy. 2008 (http://www.fao.org/3/a-i0359e.pdf). 17-11-2014.

3. Manning J, Gole V, Chousalkar K. Screening for Salmonella in backyard chickens. Preventive Veterinary Medicine 2015; 120(2): 241-245. doi: 10.1016/j. prevetmed.2015.03.019.

4. Hamilton-West C, et al. Characterization of backyard poultry production systems and disease risk in the central zone of Chile. Research in Veterinary Science 2012; 93(1): 121-124. doi: 10.1016/j.rvsc.2011.06.015.
5. Adeniyi OR, Oguntunji AO. A socio-economic survey of cultural practices and management of village poultry production in Ondo area, Nigeria. Livestock Research for Rural Development 2011; 23 (http://www.lrrd.org/ 1rrd23/12/aden23261.htm).

6. O'Donnell O. Access to health care in developing countries: breaking down demand side barriers. Cadernos de Saúde Pública 2007; 23: 2820-2834. doi: 10.1590/ S0102-311X2007001200003.

7. Betancor L, et al. Prevalence of Salmonella enterica in poultry and eggs in Uruguay during an epidemic Due to Salmonella enterica Serovar Enteritidis. Journal of Clinical Microbiology 2010; 48(7): 2413-2423. doi: 10.1128/JCM.02137-09.

8. Brenner FW, et al. Salmonella nomenclature. Journal of Clinical Microbiology 2000; 38(7): 2465-2467 (http:// jcm.asm.org/content/38/7/2465.short).

9. Zhao S, et al. Characterization of multidrug resistant Salmonella recovered from diseased animals. Veterinary Microbiology 2007; 123(1-3): 122-132. doi: 10.1016/j.vetmic.2007.03.001.

10. Grunkemeyer VL. Zoonoses, public health, and the backyard poultry flock. Veterinary Clinics of North America: Exotic Animal Practice 2011; 14(3): 477-490. doi: 10.1016/j.cvex.2011.05.010.

11. Scharff RL. Economic burden from health losses due to foodborne illness in the United States. Journal of Food Protection 2012; 75(1): 123-131. doi: 10.4315/ 0362-028X.JFP-11-058.

12. Majowicz SE, et al. The global burden of nontyphoidal Salmonella gastroenteritis. Clinical Infectious Diseases 2010; 50(6): 882-889. doi: 10.1086/650733.

13. Fica A, et al. Salmonellosis outbreaks and the size and role of the Chilean State. Revista Chilena de Infectologia 2012; 29(2): 207-214. doi: 10.4067/ S0716-10182012000200014.

14. Fresno M, et al. Identification of diverse Salmonella serotypes, virulotypes, and antimicrobial resistance phenotypes in waterfowl from Chile. Vector Borne and Zoonotic Diseases 2013; 13(12): 884-887. doi: 10.1089/ vbz.2013.1408.

15. Martínez MC, et al. Multidrug-resistant outbreakassociated Salmonella strains in irrigation water from the metropolitan region, Chile. Zoonoses and Public Health 2016; 64: 299-304.

16. ISP. Boletín Vigilancia de Laboratorio: Salmonella spp. 2012-2016. Chile. 2017 (http://www.ispch.cl/ sites/default/files/BoletinSalmonella-23012017A.pdf). 15-03-2017.

17. Leotta G, et al. Prevalence of Salmonella spp. in backyard chickens in Paraguay. International Journal of Poultry Science 2010; 9(6): 533-536. doi: 10.3923/ ijps.2010.533.536.

18. Xavier J, et al. Seroprevalence of Salmonella and Mycoplasma infection in backyard chickens in the state of Entre Ríos in Argentina. Poultry Science 2011; 90(4): 746-751. doi: 10.3382/ps.2010-01036.

19. INE. Censo Agropecuario y Forestal. Santiago, Chile. (http://www.ine.cl/estadisticas/censos/censo-agropecuario-y-forestal-2007). 2007. 
20. Alegria-Moran R, et al. Using spatial tools for high impact zoonotic agents surveillance design in backyard production systems from central Chile. Veterinaria Mexico $O A$ 2017; 4(1). doi: 10.21753/vmoa.4.1.435.

21. Dohoo R, Martin W, Stryhn H. Veterinary Epidemiologic Research, 2nd edn. Canada: VER Inc. Charlottetown, PEI, 2009, p. 865.

22. Marier EA, et al. Abattoir based survey of Salmonella in finishing pigs in the United Kingdom 2006-2007. Preventive Veterinary Medicine 2014; 117(3-4): 542553. doi: 10.1016/j.prevetmed.2014.09.004.

23. Worcman-Barninka D, et al. Evaluation of motility enrichment on modified semi-solid Rappaport-Vassiladis medium (MSRV) for the detection of Salmonella in foods. International Journal of Food Microbiology 2001; 64(3): 387-393. doi: 10.1016/S0168-1605(00)00484-0.

24. Dusch H, Altwegg M. Evaluation of five new plating media for isolation of Salmonella species. Journal of Clinical Microbiology 1995; 33(4): 802-804 (https:// www.ncbi.nlm.nih.gov/pmc/articles/PMC228044/pdf/ 330802.pdf).

25. Malorny B, et al. Multicenter validation of the analytical accuracy of Salmonella PCR: towards an international standard. Applied and Environmental Microbiology 2003; 69(1): 290-296. doi: 10.1128/AEM.69.1.290-296.2003.

26. Ranieri ML, et al. Comparison of typing methods with a new procedure based on sequence characterization for Salmonella Serovar prediction. Journal of Clinical Microbiology 2013; 51(6): 1786-1797. doi: 10.1128/ JCM.03201-12.

27. Shi C, et al. Molecular methods for serovar determination of Salmonella. Critical Reviews in Microbiology 2015; 41 (3): 309-325. doi: 10.3109/1040841X.2013.837862.

28. Kleinbaum D, Klein M. Logistic Regression: A Self-Learning Text, 3rd edn. New York: Springer, 2010.

29. Hosmer DW, et al. A comparison of goodness-of-fit tests for the logistic regression model. Statistics in Medicine 1997; 16(9): 965-980. doi: 10.1002/(SICI) 1097-0258(19970515)16:9<965::AID-SIM509>3.0. $\mathrm{CO} ; 2-\mathrm{O}$.

30. Ao T, et al. Global burden of invasive nontyphoidal Salmonella disease, 2010. Emerging Infectious Diseases 2015; 21(6): 941. doi: 10.3201/eid2106.140999.

31. Syed ST, Gerber BS, Sharp LK. Traveling towards disease: transportation barriers to health care access. Journal of Community Health 2013; 38(5): 976-993. doi: 10.1007/s10900-013-9681-1.

32. Rushton J, et al. Impact of avian influenza outbreaks in the poultry sectors of five South East Asian countries (Cambodia, Indonesia, Lao PDR, Thailand, Viet Nam) outbreak costs, responses and potential long term control. World's Poultry Science Journal 2007; 61 (3): 491-514. doi: 10.1079/WPS200570.

33. Chousalkar K, et al. Chasing Salmonella Typhimurium in free range egg production system. Veterinary Microbiology 2016; 192: 67-72. doi: 10.1016/j. vetmic.2016.06.013.

34. LV DK, Pires SM, Hald T. Attributing foodborne salmonellosis in humans to animal reservoirs in the European Union using a multi-country stochastic model. Epidemiology and Infection 2015; 143(6): 1175 1186. doi: 10.1017/S0950268814001903.

35. Jafari R, Ghorbanpour M, Jaideri A. An investigation into Salmonella infection status in backyard chickens in Iran. International Journal of Poultry Science 2007; 6: 227-229. doi: 10.3923/ijps.2007.227.229.

36. Samanta I, et al. Prevalence and antibiotic resistance profiles of Salmonella serotypes isolated from backyard poultry flocks in West Bengal, India. Journal of Applied Poultry Research 2014; 23(3): 536-545. doi: 10.3382/ japr.2013-00929.

37. Wilkins W, et al. Examining heterogeneity in the diagnostic accuracy of culture and PCR for Salmonella spp. in Swine: a systematic review/meta-regression approach. Zoonoses and Public Health 2010; 57: 121134. doi: 10.1111/j.1863-2378.2010.01366.x.

38. Rostagno MH, Eicher SD, Lay DC. Immunological, physiological, and behavioral effects of Salmonella enterica carriage and shedding in experimentally infected finishing pigs. Foodborne Pathogens and Disease 2011; 8 (5): 623-630. doi: 10.1089/fpd.2010.0735.

39. Albuquerque A, et al. Dissemination of Salmonella enteritidis by experimentally-infected pigeons. Revista Brasileira Ciência Avícola 2013; 15(3): 211-215. doi: 10.1590/S1516-635X2013000300007.

40. Koyuncu S, Andersson MG, Häggblom P. Accuracy and sensitivity of commercial PCR-based methods for detection of Salmonella enterica in feed. Applied and Environmental Microbiology 2010; 76(9): 2815-2822. doi: 10.1128/AEM.02714-09.

41. Malkawi HI, Gharaibeh R. Multiplex PCR for the direct detection of Salmonella enterica from chicken, lamb and beef food products. Journal of Basic Microbiology 2003; 43(4): 328-336. doi: 10.1002/jobm.200390035.

42. Ogunremi D, et al. Evaluation of a multiplex PCR assay for the identification of Salmonella Serovars Enteritidis and Typhimurium using retail and Abattoir samples. Journal of Food Protection 2017; 80(2): 295-301. doi: 10.4315/0362-028X.JFP-16-167.

43. Peplow MO, et al. Sensitivity, specificity, and predictive values of three Salmonella rapid detection kits using fresh and frozen poultry environmental samples versus those of standard plating. Applied and Environmental Microbiology 1999; 65(3): 1055-1060 (http://www.ncbi. nlm.nih.gov/pmc/articles/PMC91144/).

44. Li K, et al. Antimicrobial susceptibility, virulence gene and pulsed-field gel electrophoresis profiles of Salmonella enterica serovar Typhimurium recovered from retail raw chickens, China. Food Control 2017; 72 (Part A): 36-42. doi: 10.1016/j.foodcont.2016.07.032.

45. EFSA, ECDC. (European food safety authority and European centre for disease prevention and control). The European union summary report on trends and sources of zoonoses, zoonotic agents and food-borne outbreaks in 2013. EFSA Journal 2015; 13(1): 3991. doi: 10.2903/j.efsa.2015.3991.

46. Pesciaroli M, et al. Association between pigs with high caecal Salmonella loads and carcass contamination. International Journal of Food Microbiology 2017; 242: 82-86. doi: 10.1016/j.ijfoodmicro.2016.11.021. 
47. Ghoddusi A, et al. Molecular identification of Salmonella Infantis isolated from backyard chickens and detection of their resistance genesby PCR. Iranian Journal of Veterinary Research 2015; 16(3): 293-297 (http://www. ncbi.nlm.nih.gov/pmc/articles/PMC4782701/).

48. Yokoyama E, et al. A novel subpopulation of Salmonella enterica serovar Infantis strains isolated from broiler chicken organs other than the gastrointestinal tract. Veterinary Microbiology 2015; 175(2-4): 312-318. doi: 10.1016/j.vetmic.2014.11.024.

49. Basler C, et al. Notes from the field: multistate outbreak of human salmonella infections linked to live poultry from a mail-order hatchery in Ohio - FebruaryOctober 2014. Morbidity and Mortality Weekly Report - CDC 2015; 64(9): 258 (https://www.cdc.gov/mmwr/ preview/mmwrhtml/mm6409a5.htm).

50. CDC. Eight Multistate Outbreaks of Human Salmonella Infections Linked to Live Poultry in Backyard Flocks (Final Update). 2016 (https://www. cdc.gov/salmonella/live-poultry-05-16/). 25-10-2016.

51. Denagamage TN, et al. Longitudinal monitoring of successive commercial layer flocks for Salmonella enterica Serovar Enteritidis. Foodborne Pathogens and Disease 2016; 13(11): 618-625. doi: 10.1089/fpd.2016. 2146.

52. Zhao X, et al. Prevalence and characteristics of Salmonella isolated from free-range chickens in Shandong Province, China. BioMed Research International 2016; 2016: 6. doi: 10.1155/2016/8183931.
53. Bland MC. Salmonella prevention measures for small backyard flock owners. Journal of Exotic Pet Medicine 2015; 24(2): 141-155. doi: 10.1053/j.jepm.2015.04.008.

54. Haesendonck R, et al. Feral pigeons: a reservoir of zoonotic Salmonella Enteritidis strains?. Veterinary Microbiology 2016; 195: 101-103. doi: 10.1016/j.vetmic.2016.09.017.

55. Weide-Botjes M, et al. Molecular typing of Salmonella enterica subsp. Enterica serovar Hadar: evaluation and application of different typing methods. Veterinary Microbiology 1998; 61(3): 215-227. doi: 10.1016/ S0378-1135(98)00181-3.

56. Sheth AN, et al. A national outbreak of Salmonella serotype Tennessee infections from contaminated peanut butter: a new food vehicle for Salmonellosis in the United States. Clinical Infectious Diseases 2011; 53(4): 356-362. doi: 10.1093/cid/cir407.

57. Rickert-Hartman R, Folster JP. Ciprofloxacin-resistant Salmonella enterica Serotype Kentucky sequence type 198. Emerging Infectious Diseases 2014; 20(5): 910 911. doi: 10.3201/eid2005.131575.

58. Behravesh CB, et al. Backyard poultry flocks and Salmonellosis: a recurring, yet preventable public health challenge. Clinical Infectious Diseases 2014; 58(10): 1432-1438. doi: 10.1093/cid/ciu067.

59. Brioudes A, Gummow B. Understanding pig and poultry trade networks and farming practices within the pacific islands as a basis for surveillance. Transboundary and Emerging Diseases 2017; 64(1): 284-299. doi: 10.1111/ tbed.12370. 